\title{
PENINGKATAN VOLUME PENJUALAN MELALUI PELATIHAN MATERI DAN PRAKTIK DIGITAL MARKETING BAGI PARA PELAKU USAHA KECIL MIKRO-PERTANIAN KOTA DEPOK (UKM-P)
}

\author{
Vivi Iswanti Nursyirwan ${ }^{a, 1}$, Sasmita Sari Ardaninggar ${ }^{b, 2}$, Liana Dwi Septiningrum ${ }^{c, 3}$, Dewi Rani \\ Gustiasari $^{\mathrm{d}, 4}$, Julian Muhammad Hasan ${ }^{\mathrm{e}, 5}$ \\ S-1 Akuntansi, Ekonomi, Universitas Pamulang * \\ dosen02226@unpam.ac.id
}

\begin{abstract}
Abstrak
Pengabdian kepada masyarakat yang dilakukan oleh Tim Dosen Fakultas Ekonomi Prodi Akuntansi Universitas Pamulang ini dilakukan dengan mengadakan pelatihan edukasi menggunakan metode ceramah, tanya jawab, praktik dan diskusi kepada para pelaku usaha kecil mikro pertanian mengenai pentingnya kegiatan pemasaran baik berbasis offline/konvensional marketing, maupun berbasis online marketing. Program ini bermitra dengan para pelaku usaha kecil mikro pertanian di Kota Depok, khususnya di kecamatan Sukmajaya Kota Depok. Permasalahan utama yang dihadapi mitra adalah keterbatasan pengetahuan dan ketrampilan dalam memasarkan produk olahan pertanian baik secara offline maupun online. Program edukasi diberikan dengan bantuan media audiovisual infocus, serta dengan memberikan pelatihan berbasis teori pemasaran dan praktik langsung kegiatan pemasaran berbasis digital oleh Dosen Marketing serta berkolaborasi dengan Pakar Digitalpreneur. Tujuan utama kegiatan pengabdian ini untuk memberikan pemahaman dan pengetahuan para pelaku usaha berkaitan dengan the power of marketing dalam dunia usaha. Pelatihan dilaksanakan pada tanggal 1-3 Oktober 2019, bertempat di balai pelatihan koperasi Kota Depok. Evaluasi kegiatan yang digunakan dalam pengabadian masyarakat ini adalah aspek pengetahuan dan keterampilan. Hasil kegiatan pengabdian menyatakan bahwa peserta pelatihan mendapatkan peningkatan aspek kognisi dan skill sebesar 27,27\% dari sebelum adanya pelatihan..
\end{abstract}

Kata-kata kunci: UMKM; Marketing; Pelatihan

\begin{tabular}{l} 
Abstract \\
\hline Service to the community conducted by the Lecturer Team of the Faculty of Economics \\
of the University of Pamulang Accounting is conducted by conducting educational \\
training using lecture methods, questions and answers, practices and discussions to \\
micro-small business entrepreneurs about the importance of marketing activities both \\
offline / conventional based, and based online marketing. This program is partnering \\
with micro agriculture micro entrepreneurs in Depok City, especially in Sukmajaya \\
Sub-District, Depok City. The main problem faced by partners is the limited knowledge \\
and skills in marketing agricultural processed products both offline and online. The \\
education program is given with the help of audiovisual infocus media, as well as by \\
providing training in marketing theory based and direct practice of digital based \\
marketing activities by Marketing Lecturers and in collaboration with Digitalpreneur \\
Experts. The main purpose of this community service activity is to provide \\
understanding and knowledge of business actors relating to the power of marketing in \\
the business world. The training was held on 1-3 October 2019, at the Depok City \\
\hline
\end{tabular}


cooperative training center. The evaluation of activities used in community service is an aspect of knowledge and skills. The results of the service activities stated that the training participants got an increase in the aspects of cognition and skills by $27.27 \%$ from before the training.

Keywords: UMKM; Marketing; Training

\section{PENDAHULUAN}

Letak Kota Depok sangat strategis apabila dilihat dari segi politik, ekonomi, sosial budaya dan pertahanan keamanan karena berbatasan langsung dengan ibukota Jakarta sebagai pusat pemerintahan dan ekonomi. Kota Depok memiliki potensi sebagai sebuah wilayah penyangga yang menjadikan kawasan lalu lintas JakartaDepok-Bogor-Tangerang-Bekasi， satu sisi potensi ini mendukung untuk dijadikan sebagai tempat bermukim, berusaha dan sebagai daerah pemerintahaan. Berdasarkan struktur ekonomi, potensi unggulan daerah Kota Depok adalah sektor tersier yang meliputi sektor perdagangan, hotel dan restoran, dan sub sektor jasa. Sukmajaya adalah salah satu kecamatan di kabupaten Depok, Provinsi Jawa Barat, dengan jumlah penduduk 31.191 jiwa. Di wilayah kecamatan Sukmajaya terdapat 1.658 wiraswasta tersebar di wilayah dengan luas $3,29 \mathrm{~km} 2$. Jumlah pedagang di wilayah kecamatan Sukmajaya pada tahun 2018 sejumlah 128.
Masyarakat di Kecamatan Sukmajaya yang berprofesi sebagai pelaku usaha sebagian tergabung dalam komunitas usaha kecil mikro pertanian (UKM-P). UKM-P merupakan komunitas bagi para pelaku usaha kecil mikro yang bergerak di bidang hasil olahan pertanian, seperti : produsen jamu kunyit asam, produsen siomay, produsen peyek kacang, produsen empekempek, produsen makanan tradisional, produsen sari lemon, produsen kembang goyang dan sebagainya. UKM Pertanian terdiri dari 200 pelaku usaha kecil mikro yang tersebar di 11 wilayah Kecamatan Kota Depok, Jawa Barat. Fokus kegiatan kami adalah pada kecamatan Sukmajaya Kota Depok.

Berdasarkan observasi awal kepada para pelaku usaha yang tergabung di komunitas usaha kecil mikro pertanian (UKM-P) Kota Depok, pelaku usaha saat ini menyampaikan keluhan atas keterbatasan pengetahuan dalam dunia pemasaran, baik secara offline/konvensional marketing, maupun secara online marketing. Para pelaku usaha menyampaikan keluhan terkait 
penurunan omset penjualan. Salah satu fenomena yang berada di sekitar para pelaku usaha saat ini adalah maraknya kompetitor yang menjual produk dan layanan yang berbasis online marketing. Hal ini menjadi satu kendala bagi para pelaku usaha, mengingat para pelaku usaha saat ini belum menguasai pentingnya kegiatan pemasaran, terlebih berbasis digital.

Keterbatasan pengetahuan dan ketrampilan dari para pemilik usaha di bawah naungan UKM-P terkait ilmu pemasaran baik dari sisi offline maupun online marketing mengakibatkan omset penjualan produk yang tidak optimal. Bahkan, berdasarkan hasil observasi tim pengabdian masyarakat pelaku usaha menyatakan keluhannya terkait menurunnya omset/sales volume penjualannya. Penurunan volume penjualan disinyalir karena banyaknya kompetitor sejenis yang memanfaatkan kegiatan pemasaran khususnya dari sisi online marketing yang berdampak terhadap pasar sasaran para pelaku usaha di kecamatan sukmajaya Kota Depok. Para pelaku usaha saat ini sebetulnya menginginkan juga untuk dapat bertumbuh dalam hal usaha, namun saat ini para pelaku usaha terkendala atas pengetahuan dan strategi pemasaran yang tepat untuk dapat membantu peningkatan omset penjualan usahanya. Oleh karena itu perlu dilakukan kegiatan pelatihan kepada para pelaku usaha kecil mikro pertanian di Kecamatan Sukmajaya berkaitan dengan pentingnya aktifitas kegiatan pemasaran berbasis offline dan online marketing untuk meningkatkan jangkauan pemasaran serta untuk meningkatkan volume penjualan.

Adrianah (2017) menyatakan bahwa terdapat pengaruh bauran pemasaran terhadap volume penjualan. Berdasarkan situasi dan penelitian tersebut, maka pelaksanaan kegiatan pengabdian kepada masyarakat ini adalah bagaimana para akademisi dalam membantu peningkatan volume penjualan melalui kegiatan pelatihan pemasaran bagi para pelaku usaha kecil mikro pertanian (UKM-P) Kota Depok.

\section{METODE}

Permasalahan utama mitra adalah keterbatasan pengetahuan dan keterampilan para pelaku usaha kecil mikro pertanian Kota Depok di Kecamatan Sukmajaya yang tergabung dalam komunitas UKM-Pertanian (UKM-P) Kota Depok dalam ilmu pemasaran, baik konvensional marketing maupun online marketing. Berkaitan dengan permasalahan mitra, kegiatan pengabdian masyarakat dilaksanakan berupa pelatihan. Metode yang digunakan adalah ceramah, tanya jawab, diskusi dan praktek yang di berikan oleh para Dosen Marketing dan praktisi Digitalpreneur untuk sesi praktik kegiatan pemasaran digital. 
Kegiatan pengabdian masyarakat diawali dengan tahapan persiapan. Tahapan persiapan meliputi observasi untuk mengetahui kondisi faktual kebutuhan para pelaku usaha kecil mikro pertanian Kecamatan Sukmajaya Kota Depok. Pada tahap ini diketahui bahwa para pelaku usaha kecil mikro pertanian Kota Depok khususnya di Kecamatan Sukmajaya belum memilki pemahaman yang cukup terkait ilmu pemasaran baik berbasis offline marketing dan online marketing. Diketahui pula bahwa kegiatan pemasaran yang dilakukan saat ini masih sangat sederhana, dan belum memanfaatkan strategi pemasaran yang berarti, terlebih pemasaran berbasis digital. Pemasaran digital belum optimal dilakukan oleh para pelaku usaha, berbanding terbalik dengan aktifitas pemasaran yang dilakukan oleh kompetitornya. Setelah di ketahui kondisi riil, tim pengabdian melakukan tahap persiapan kegiatan pelatihan berupa: persiapan tempat/lokasi pelatihan, persiapan waktu yang relevan untuk penyelenggaraan pelatihan, persiapan narasumber pelatihan, persiapan materi pelatihan, persiapan metode pengukuran kegiatan pelatihan, persiapan perlengkapan pelatihan, persiapan peserta pelatihan sebanyak sekitar 30 orang dari para pelaku usaha kecil mikro pertanian di Kecamatan Sukmajaya Kota Depok, dan lain-lain. Kegiatan pelatihan melibatkan 1 narasumber Dosen Marketing, dan 1 orang
Praktisi Digitalpreneur, Bapak Kenang Prasetyo, serta dengan melibatkan para Dosen Ekonomi Akuntansi S1 Universitas Pamulang dan 2 orang Mahasiswa Universitas Pamulang.

Tahapan kedua setelah persiapan adalah tahapan pelaksanaan. Kegiatan pengabdian masyarakat dilakukan dalam bentuk pelatihan. Pelatihan dilaksanakan selama 3 hari, yakni pada tanggal 1 Oktober3 Oktober 2019, bertempat di Balai Pelatihan Koperasi Kota Depok.

Pelaksananaan kegiatan pelatihan dilaksanakan dengan pemberian materi terkait pemasaran terlebih dahulu setelah itu dilaksanakan kegiatan praktik kegiatan pemasaran berbasis digital. Pada tahapan awal pelaksanaan kegiatan pengabdian tim dosen membagikan kuisioner yang sudah dipersiapkan diawal untuk mengukur aspek kognisi dan keterampilan peserta pelatihan sebelum kegiatan pengabdian berlangsung.

Monitoring dan Evaluasi kegiatan merupakan tahapan ketiga setelah tahapan pelaksanaan kegiatan. Pada tahap ini dilakukan penilaian :

1. Menilai kemampuan peserta pelatihan dalam aspek kognisi strategi pemasaran yang tepat sebagai sarana pemasaran produk/layanannya

2. Menilai kemampuan peserta dalam aspek keterampilan penggunaan layanan marketing berbasis digital 
3. Menilai tingkat keaktifan peserta dalam kegiatan pelatihan

4. Menilai tingkat kehadiran peserta selama kegiatan berlangsung
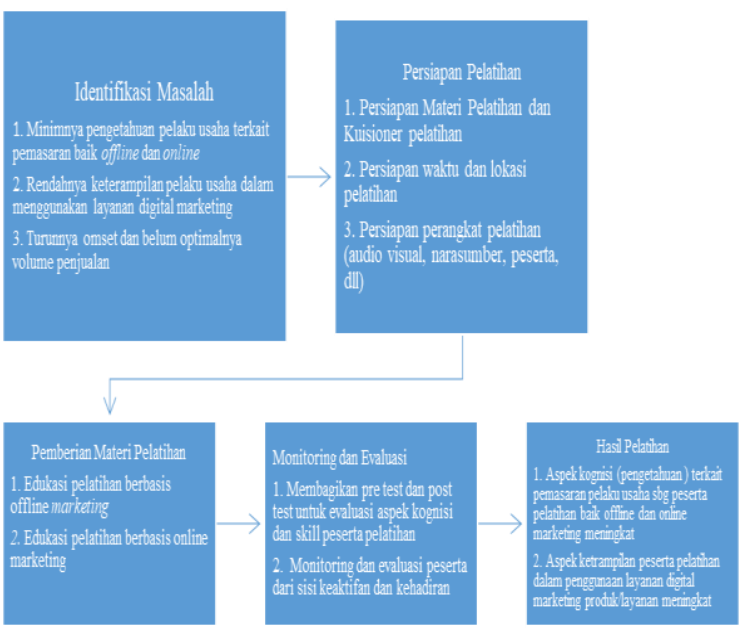

Gambar 1. Bagan Alir Kegiatan Pengabdian Kepada Masyarakat

\section{HASIL DAN PEMBAHASAN}

Kegiatan Pengabdian Masyarakat yang dilakukan oleh Tim Dosen Fakultas Ekonomi Jurusan Akuntansi S1 Universitas Pamulang ini ditujukan kepada para pelaku usaha kecil mikro pertanian (UKM-P) Kota Depok. Kegiatan pengabdian berupa pemberian pelatihan berupa materi pemasaran berdasarkan teori dan praktik langsung ini dibawakan oleh Dosen Marketing dan Praktisi Digitalpreneur. Kegiatan diselenggarakan selam 3 hari, yakni pada tanggal 1 Oktober sampai dengan 3 Oktober 2019, bertempat di Balai Pelatihan Koperasi Kota Depok. Pada hari pertama dilakukan pemberian materi implementasi penetapan strategi pemasaran dalam rangka peningkatan volume penjualan. Dihari berikutnya merupakan kegiatan pelatihan praktik pemanfaatan layanan digital marketing dalam meningkatkan jangkauan pemasaran. Di hari terakhir, kegiatan pelatihan beragendakan tanya jawab terkait hambatan teknis para pelaku usaha kecil mikro pertanian (UKM-P) dalam melakukan kegiatan pemasaran, khususnya berbasis digital.

Peserta kegiatan ini adalah para pemilik usaha di bawah naungan komunitas usaha kecil mikro pertanian (UKM-P) Kecamatan Sukmajaya, Kota Depok. Pelaku usaha mayoritas bergerak disektor produk olahan hasil pertanian, diantaranya : produsen sari lemon, produsen jamu kunyit asam, produsen jus buah segar, produsen empek-empek, produsen makanan tradisional, dan lain-lain. Selama ini cara pemasaran yang dilakukan para pelaku usaha masih konvensional dan belum banyak memanfaatkan online marketing. Beberapa pelaku usaha sudah ada yang menggunakan digital marketing, seperti pemasaran berbasis sosial media, diantaranya facebook, whatsapp group, dan lain-lain, namun belum maksimal.

Frekuensi kehadiran peserta pelatihan saat berlangsungnya acara pelatihan berdasarkan daftar presensi ialah : a). 
pertemuan $1: 36$ orang pada hari pertama $b$ ). 35 orang pada hari kedua c). 27 orang pada hari ketiga.

Sebelum pelatihan Tim Dosen sudah menyiapkan pre-test untuk dibagikan kepada para peserta pelatihan. Begitu pula setelah pre-test, peserta pelatihan diberikan kembali kuisioner untuk mengukur aspek kognisi dan ketrampilan peserta pelatihan baik sebelum dan setelah pelatihan berlangsung.

Selama pelatihan berlangsung, peserta sangat antusias dan dengan sunguhsungguh terlibat aktif dalam memperhatikan kegiatan pelatihan terlebih saat kelas praktik pelatihan berlangsung. Peserta pelatihan juga tidak jarang dalam menanyakan langsung kepada presenter jika terdapat ketidakpahaman atas materi yang diberikan.

Selama pelatihan berlangsung terpancar rasa antusias dari para pelaku usaha kecil mikro pertanian atas terselenggaranya kegiatan pelatihan ini. Bagi para pelaku usaha (UKM-P) kegiatan ini sangat menarik dan bermanfaat untuk meningkatkan volume penjualan mereka.

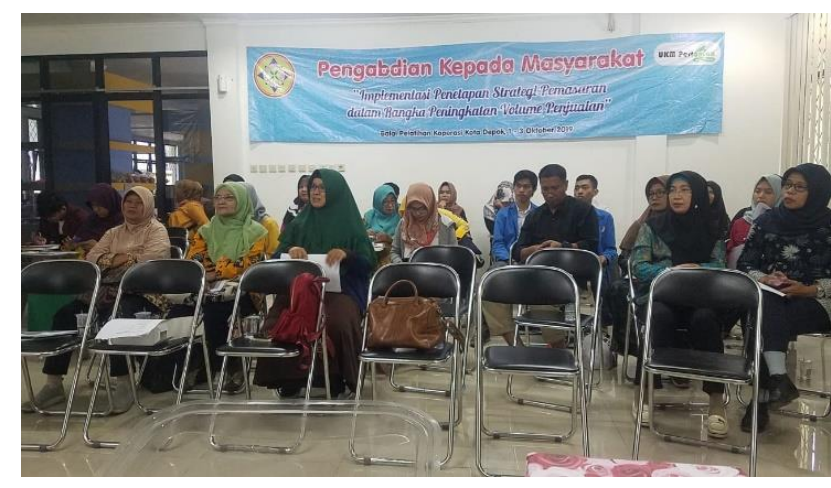

Gambar 2. Pemberian Materi oleh Tim Pengabdian Masyarakat

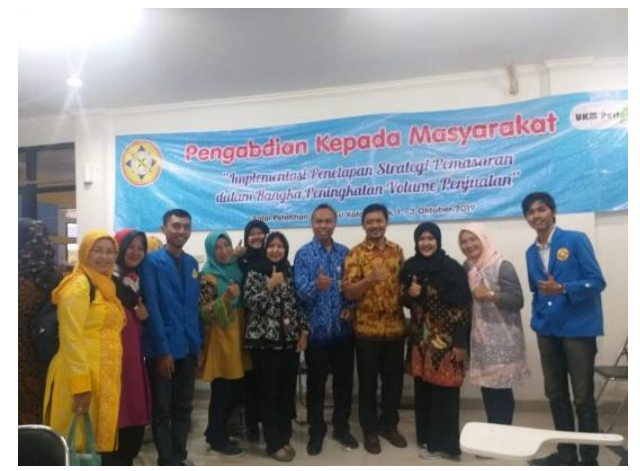

Gambar 3. Tim Pengabdi bersama Pakar Digitalpreneur dan Perwakilan Balai Pelatihan Koperasi Kota Depok dan beberapa peserta pelatihan

Berdasarkan hasil post test dan hasil pengamatan tim pengabdian masyarakat, peserta kegiatan pelatihan dapat mempraktikan materi terkait pemasaran dengan cukup baik. Hasil post test juga menunjukan peningkatan sebesar 27, 27\% dari aspek kognisi dan skill peserta pelatihan.

Hasil dari implementasi kegiatan pengabdian kepada masyarakat yang dilaksanakan oleh tim Dosen Universitas Pamulang bersama dua Mahasiswa Universitas Pamulang telah berhasil memberikan pemahaman terkait pentingnya offline dan online marketing di dunia usaha saat ini. Peserta pelatihan khususnya para pelaku usaha kecil mikro pertanian (UKM-P) Kecamatan Sukmajaya Kota Depok menyambut dengan sangat hangat dan menginginkan agar terlaksananya kegiatan pelatihan pemasaran secara berkala. Besar harapan para pelaku usaha agar dapat 
meningkatkan kemampuannya dalam kegiatan pemasaran baik offline dan online marketing yang pada akhirnya akan berdampak pada peningkatan volume penjualan dan juga kesejahteraan para pelaku usaha tersebut.

\section{SIMPULAN DAN SARAN}

Proses identifikasi masalah yang tepat dalam merumuskan kegiatan pengabdian masyarakat merupakan aspek penting yang dapat membantu matangnya persiapan kegiatan pengabdian masyarakat. Menjawab identifikasi masalah secara relevan dengan kebutuhan para pelaku usaha sebagai peserta pelatihan merupakan hal yang tak kalah penting. Kegiatan pelatihan berbasis edukasi secara offline dan online marketing merupakan kebutuhan para pelaku usaha kecil mikro pertanian (UKM-P) Kota Depok, khususnya di Kecamatan Sukmajaya. Pendekatan pelatihan berupa ceramah, praktik, diskusi dan tanya jawab menjadikan peserta pelatihan dapat berdialog secara interaktif dengan presenter sehingga hal-hal yang menjadi kendala saat kegiatan pemasaran berlangsung dapat ditindaklanjuti solusinya.
Pelatihan yang dilaksanakan tim Pengabdian Masyarakat bersinergi dengan praktisi Digitalpreneur telah dapat mencapai tujuan yang diharapkan, yaitu peningkatan aspek kognisi dan skill dari peserta pelatihan khususnya dari sisi digital marketing.

\section{REFERENSI}

Adrianah (2017) Pengaruh Bauran Pemasaran Terhadap Volume Penjualan pada PT. Ardan Masogi TBK di Kota Pare-Pare dalam Jurnal Ekonomi Volume 5 nomor 1

BPS Kota Depok (2019) Kecamatan Sukmajaya Dalam Angka Tahun 2019. BPS Kota Depok

Ericson Damanik (2013). Pengertian Volume

Penjualan. PT. Indeks Kelompok Gramedia , Jakarta (diakses pada 24 Oktober 2019).

Kotler,Philip\&Armstrong, Gary (2014). Prinsip-prinsip Manajemen

Pemasaran. Edisi 14, Jilid 1. Jakarta : Erlangga. 